\title{
Management of Otological Foreign Bodies Impaction in Tertiary Health Care Center
}

\author{
Waheed Atilade Adegbiji ${ }^{1}$, Shuaib Kayode Aremu ${ }^{2}$, AbdulAkeem A. Aluko ${ }^{3}$, Olawale Olubi ${ }^{4}$ \\ ${ }^{1}$ ENT Department, Ekiti State University Teaching Hospital, Ado Ekiti \\ ${ }^{2}$ ENT Department, Federal Teaching Hospital Ido-Ekiti, Ekiti State/Afe-Babalola University Ado-Ekiti \\ ${ }^{3}$ ENT Department, Bayero University/ Aminu Kano Teaching hospital, Kano, Nigeria \\ ${ }^{4}$ ENT Department, Lagos State University Teaching Hospital, Lagos
}

Address of Correspondence - Shuaib Kayode Aremu, Email - shuaib.aremu @ gmail.com

Received 12 January 2019; $\quad$ Accepted 25 January 2019;

Published 01 February 2019

\begin{abstract}
Background: Otologic foreign body impaction are common ear disorder with an associated challenge due to high levels with of pre-hospital unskilled attempted removal.

Aim: This study aimed at determining the prevalence, socio-demographic features, etiology, clinical presentation, management and outcome in a tertiary health care center in Nigeria.

Materials and Methods: This is a prospective hospital-based study of all patients with an impacted otologic foreign body. Consented patients were studied between October 2015 and September 2017. The interviewer-assisted questionnaire was used to collect data. Analysis of obtained data was done SPSS version 16.0.

Results: Prevalence of otologic foreign body impaction was 4.5\%. There were 58.5\% males with a male to female ratio of 1.5:1.

The main type of ear foreign body impaction was $85.2 \%$ organic (living or dead) and $14.8 \%$ inorganic. Commonest otologic foreign body were a cotton bud, insects and seeds in $38.5 \%, 17.0 \%$ and $11.9 \%$ respectively.

The foreign body was unilateral in $97.0 \%$ and bilateral in $3.0 \%$. Left ear in $42.2 \%$ and right ear in $54.8 \%$. The foreign body was in the external canal in $97.8 \%$ and middle ear cleft in $2.2 \%$.

Main sources of referral were self-reporting in $30.4 \%$ and general practitioners in $22.2 \%$.

Commonest predisposing factors were $31.1 \%$ allergy, $23.7 \%$ otitis externa, $15.6 \%$ earwax and $3.0 \%$ mental disorders.

Conclusion: There are the different type of otology foreign body in all age group and associated predisposing factors. Pre-hospital attempt removal by unskilled sympathizers and untrained health workers leads to avoidable complications.
\end{abstract}

Keywords: Otology, Ear, Foreign body impaction, Ekiti

\section{Introduction}

Otological foreign body impaction is a condition of immovable lodgement of an object that can only be removed by skilled intervention. Otologic foreign bodies vary widely in type, shape and size, and chemical components. Foreign bodies in the ear may be organic or inorganic ${ }^{[1]}$. Inorganic usually asymptomatic and discovered incidentally includes beads, buttons, stones, paper, broken parts toys and plastic ${ }^{[2]}$. Organic foreign bodies in the ear produce earlier tissue reaction and symptoms because they lead to irritation of the external auditory canal epithelium or middle ear cleft mucosa leading to secretion and they include seed, cotton bud, insects, and so on ${ }^{[3]}$. Type of foreign body insertion depends on the availability of the objects and absence or presence of watchful caregivers $^{[4-6]}$.
Otologic foreign body impaction is one of the common presentations in Otorhinolaryngology, head and neck practice worldwide $^{[7-9]}$. It is one of the commonest emergency condition in developing and low-income country ${ }^{[7,9]}$. Aural foreign body impaction is commoner in children than adults.

Insertion of an object in the ear could be deliberate or accidental. Deliberate foreign body insertion is by curiosity or desire to explore orifices, imitation, boredom, fun making, mental retardation, insanity among others. This is very common in children $^{[7,8]}$. Accidental insertion is from personal hygiene, road traffic accident or missile injuries to the ear commonly in adults patients $^{[10]}$.

Initial foreign body impacted in the external auditory canal may be further dislodged into middle ear cleft. This occurred from 
untrained hand attempted removal by sympathizers which includes father, mother and neighborhood ${ }^{[11,12]}$. This may also occur from unskilled primary health workers. Various form of methods and inappropriate object were predominantly used.

There are various obstacles to time removal of impacted aural foreign body. In developing countries, the major barriers include the availability of otorhinolaryngology, head and neck surgeon, a distance of the tertiary health institution, transportation, fund and so on ${ }^{[13,14]}$.

This study aimed at determining the prevalence, sociodemographic features, etiology, clinical presentation management and outcome of otologic foreign bodies in a tertiary care center in sub-Sahara, Africa.

\section{Materials and Methods}

This was a prospective hospital-based study of patients with clinical features of otological foreign bodies in the Ear, Nose and Throat Department of Ekiti State University Teaching Hospital, Ado Ekiti, Nigeria. The study was carried out between January 2015 and December 2017. All the patients with features of otological foreign bodies were enrolled in the study. Data obtained from the patient during the study included demographic data; presenting symptoms, duration of symptoms, nature of objects and Pre-hospital and hospital management. These were followed by detailed ear, nose and throat examination. Findings of the detailed clinical examinations were documented particularly otoscopic findings. The diagnosis of otological foreign bodies in each patient was based on history and clinical findings. Treatment techniques for the removal of the ear foreign bodies were noted and documented. All associated complications from the foreign bodies or with pre-hospital and hospital treatments were also noted.

Data were obtained by using a pretested interviewers assisted questionnaire. All data obtained were documented.

All data were collated and analyzed using SPSS version 16.0. The data were expressed by frequency table, percentage, bar charts, and pie charts.

Ethical clearance for this study was sought for and obtained from the ethical committee of the institution.

\section{Results}

During this study period, a total of 2987 patients were seen in ear, nose and throat department out of whichy135 of whom had ear foreign body. Prevalence of otologic foreign body impaction was $4.5 \%$.

In this study, the major prevalence of the ear foreign body impactions was 52 (38.5\%) found in the younger age group (1-10). Age group distribution of the patients is shown in table 1 .

On the sociodemographic features, there were 79 (58.5\%) males and $56(41.5 \%)$ females with a male to female ratio of 1.5:1. Urban dwellers in 80 (59.3\%) were predominant over rural dwellers in 55 (40.7\%). The commonest form of education among the patients was preschool, primary and secondary in 43 (31.9\%), 39 (28.9\%) and $28(20.7 \%)$ respectively. Majority of the occupation were 49 (36.3\%) students/apprentice, $17(12.6 \%)$ driver and $17(12.6 \%)$ artisans. Others were farming in $11(8.1 \%)$ and business in 11 (8.1\%. Table 2 illustrated the sociodemographic features of patients with ear foreign body.

The main type of ear foreign body impaction was $115(85.2 \%)$ organic (living or dead) foreign body and 20 (14.8\%) inorganic foreign body. Commonest otologic foreign body were cotton bud, insects and seeds in 52 (38.5\%), $23(17.0 \%)$ and $16(11.9 \%)$ respectively. Less common foreign body impaction was biro cover, maggot and match stick in $2(1.5 \%), 3(2.2 \%)$, and $3(2.2 \%)$ respectively. Table 3 demonstrated pattern of foreign body

The anatomical location of ear foreign body impaction was unilateral ear foreign body in 131 (97.0) and bilateral ear foreign body in $4(3.0 \%)$. The left nasal foreign body was less common than the right nasal foreign body in $57(42.2 \%)$ and $74(54.8 \%)$ respectively. Ear foreign body impaction was founded in the external auditory canal in $132(97.8 \%)$ and middle ear cleft in 3 (2.2\%). Table 4 showed the anatomical distribution of ear foreign body.

In this study, major sources of referral were self-reporting in 41 $(30.4 \%)$ and general practitioners in $30(22.2 \%)$. Minor sources of referral were from the pediatrician in $28(20.7 \%)$ and casualty officer in $22(16.3 \%)$. The components of other sources of referral include $3(2.2 \%)$ traditional healers and 7 (5.2\%), spiritual healers. Figure 1 Sources of referral among the patients.

Commonest mode of presentation in this study was foreign body impaction in $134(99.3 \%)$, otalgia in $106(78.5 \%)$ and hearing impairment in $96(71.1 \%)$. Others were a perforated tympanic membrane in 7 (5.2\%) and vertigo in $9(6.7 \%)$. Single episodes of foreign body impaction in $132(97.8 \%)$ was commoner than recurrent episodes of foreign body impaction in $3(2.2 \%)$ patients. Table 5 demonstrated clinical features of the otological foreign body.

There were acute foreign body presentation in 134 (99.3\%) and commoner than chronic foreign body impaction $(\geq 13$ weeks) presentation in $1(0.7 \%)$. Common acute presentation was (1-4) weeks in $97(71.9 \%)$ and (5-8) weeks in 31 (23.0\%). Symptoms duration of the foreign body is illustrated in figure 2 .

In this study, commonest predisposing factors for otologic foreign body impaction were $42(31.1 \%)$ allergy, $32(23.7 \%)$ otitis externa, $21(15.6 \%)$ earwax and $4(3.0 \%)$ mental disorders. Figure 3 demonstrated predisposing factors for otologic foreign body impaction.

Common disability associated with otologic foreign body impaction in this study were anxiety, irritable and absenteeism in $76(43.2 \%), 79(44.9 \%)$ and $86(48.9 \%)$ respectively. Disability associated with foreign body impaction were shown in figure 4 .

In this study $86(63.7 \%)$ and $48(35.6 \%)$ were treated in the ear, nose, and throat outpatients clinic and were treated in accident and emergency department respectively. In the management of otological foreign body impaction, $132(97.8 \%)$ objects were visualized, 3(2.2\%) objects were not visualized who had radiological imaging, $1(0.7 \%)$ of which were radio-opaque objects. All the patients had the foreign body removed. Prehospital treatment occurred in $91(67.4 \%)$ of the studied patients. $56(41.5 \%)$ of the patients had conservative/medical treatment. 
Bleeding control was done in $42(31.1 \%)$ patients. In this study, commonest associated complications of the impacted foreign body were $32(23.7 \%)$ otitis externa and $26(19.3 \%)$ hearing loss. The other was otitis media in 7 (5.2\%). 129 (95.6\%) patients had a foreign body removed without anesthesia while 6 (4.5\%) foreign body was removed under anesthesia. $114(84.4 \%)$ patients were satisfied with the hospital treatment intervention while $21(15.6 \%)$ patients were not satisfied. Table 5 illustrated management of the foreign body.

Table 1: Age group distribution of the patients

\begin{tabular}{|c|c|c|}
\hline Age group (year) & Number & Percentage (\%) \\
\hline $1-10$ & 52 & 38.5 \\
$11-20$ & 33 & 24.4 \\
$21-30$ & 29 & 21.5 \\
$31-40$ & 9 & 6.7 \\
$41-50$ & 8 & 5.9 \\
$51-60$ & 3 & 2.2 \\
$\geq 61$ & 1 & 0.7 \\
\hline & & \\
\hline
\end{tabular}

Table 2: Sociodemographic features of patients with ear foreign body

\begin{tabular}{|l|c|c|}
\hline Sociodemographic features & Number & Percentage (\%) \\
\hline Sex & 79 & 58.5 \\
Male & 56 & 41.5 \\
Female & & \\
Residential & 80 & 59.3 \\
Urban & 55 & 40.7 \\
Rural & & \\
Education level & 43 & 31.9 \\
Preschool & 39 & 28.9 \\
Primary & 28 & 20.7 \\
Secondary & 25 & 18.5 \\
Post-secondary & & \\
Occupation & 49 & 36.3 \\
Student/Apprentice & 15 & 11.1 \\
Applicant & 14 & 10.4 \\
Business & 17 & 12.6 \\
Driver & 12 & 8.9 \\
Industrial worker & 11 & 8.1 \\
Farming & 17 & 12.6 \\
Artisans & & \\
\hline \multicolumn{2}{|}{} & \\
\hline
\end{tabular}

Table 3: Pattern of ear foreign body

\begin{tabular}{|l|c|c|}
\hline Etiology & Number & Percentage (\%) \\
\hline Paper & 12 & 8.9 \\
Matchsticks & 3 & 2.2 \\
Toothpick & 4 & 3.0 \\
seeds & 16 & 11.9 \\
Maggot & 3 & 2.2 \\
Chalk & 5 & 3.7 \\
Insects & 23 & 17.0 \\
Battery & 4 & 3.0 \\
Cotton bud & 52 & 38.5 \\
Bead & 11 & 8.1 \\
Biro cover & 2 & 1.5 \\
\hline & 135 & \\
\hline
\end{tabular}

Table 4: Anatomical location of ear foreign body among the patients

\begin{tabular}{|l|c|c|}
\hline Anatomical location & Number & Percentage (\%) \\
\hline Lateralization & 57 & 42.2 \\
Left & 74 & 54.8 \\
Right & 4 & 3.0 \\
Bilateral & & \\
Location & 132 & 97.8 \\
External auditory canal & 3 & 2.2 \\
Middle ear cleft & 0 & 0 \\
Inner ear & & \\
\hline & & \\
\hline
\end{tabular}

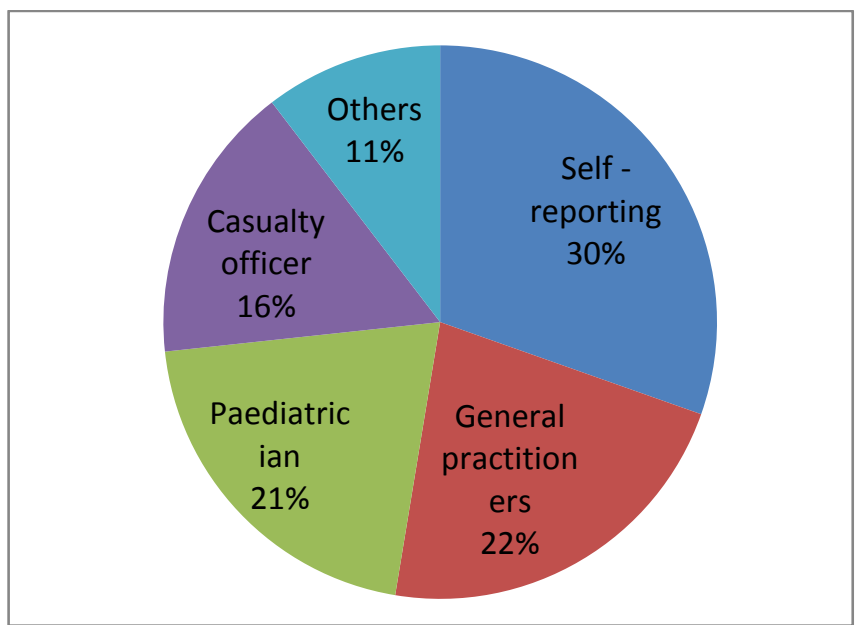

Figure 1: Sources of referral among the patients

Table 5: Clinical features of ear foreign body among the patients

\begin{tabular}{|l|c|c|}
\hline Clinical features & Number & Percentage (\%) \\
\hline Foreign body impaction & 134 & 99.3 \\
Hearing loss & 96 & 71.1 \\
Vertigo & 9 & 6.7 \\
Otalgia & 106 & 78.5 \\
Tinnitus & 48 & 35.6 \\
Lacerations & 64 & 47.4 \\
Bleeding & 62 & 45.9 \\
Perforated tympanic membrane & 7 & 5.2 \\
\hline & & \\
\hline
\end{tabular}

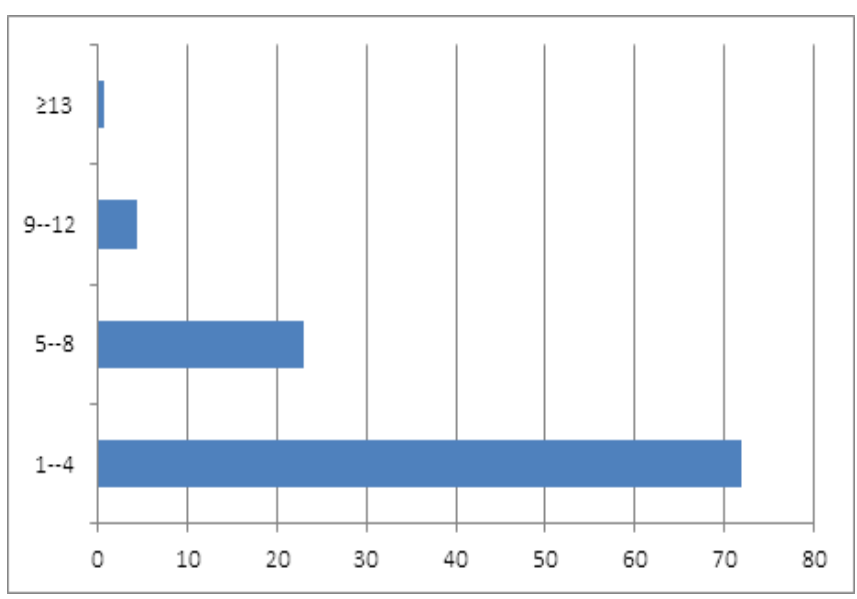

Figure 2: Symptoms duration of ear foreign body 


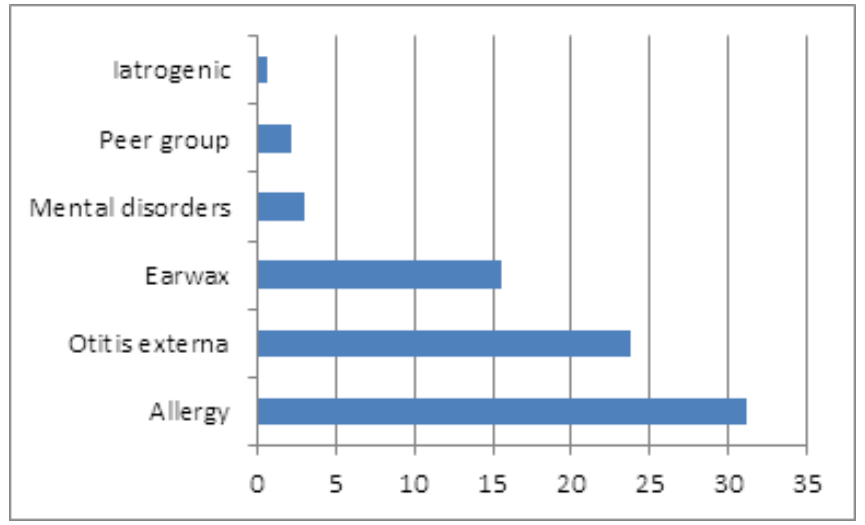

Figure 3: Predisposing factors for otologic foreign body impaction

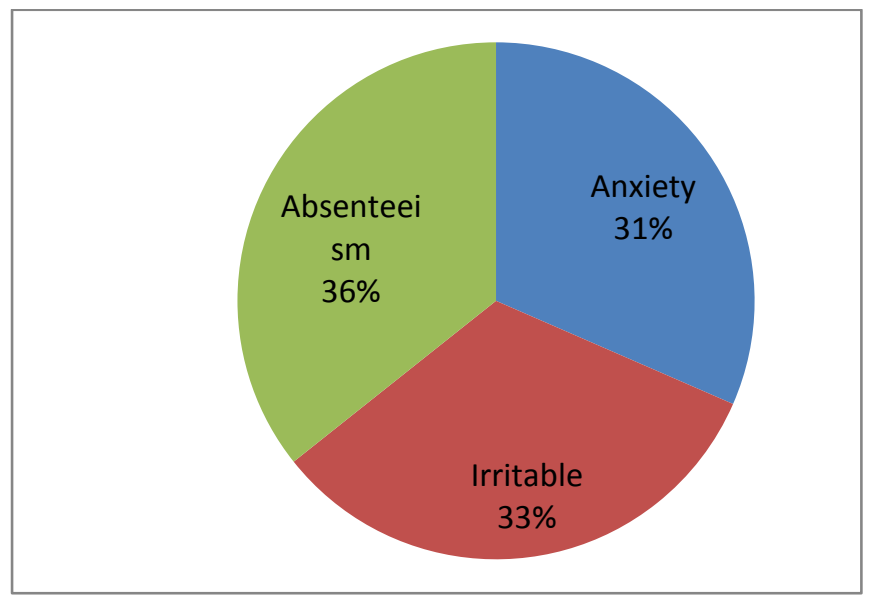

Figure 4: Disability associated with foreign body impaction

Table 6: Management pattern among the patients

\begin{tabular}{|l|c|c|}
\hline Treatment patterns & Number & $\begin{array}{c}\text { Percentage } \\
\mathbf{( \% )}\end{array}$ \\
\hline Location of treatment & 86 & 63.7 \\
Ear Nose and Throat clinic & 1 & 0.7 \\
Hospital ward & 48 & 35.6 \\
Accident and emergency department & & \\
Management & 91 & 67.4 \\
Pre-hospital treatment & 56 & 41.5 \\
Conservative/medical treatment & 135 & 100 \\
Foreign body removal & 42 & 31.1 \\
Bleeding control & & \\
Associated compilations & 7 & 5.2 \\
Otitis media & 32 & 23.7 \\
Otitis externa & 26 & 19.3 \\
Hearing loss & 7 & 5.2 \\
Perforated tympanic membrane & & \\
Type of Anaesthesia & 129 & 95.6 \\
No anesthesia & 6 & 4.5 \\
General anesthesia & & \\
Patients satisfaction & 114 & 84.4 \\
Satisfactory & 21 & 15.6 \\
Unsatisfactory & & \\
\hline & & \\
\hline
\end{tabular}

\section{Discussion}

In this study, the prevalence of otology foreign body impaction was $4.5 \%$. These findings, in contrast, to report from other studies $^{[15]}$. High prevalence in this work may be due to more reported cases of ear foreign body impaction. Some proportion of patients still patronize alternative medicine. Pre-hospital care among the studied patients was high in our center. Majority of the studied patients were children, male and urban dwellers as documented in other studies ${ }^{[15-17]}$. This is because children by nature are inquisitive and like to explore various orifices in their body, the male is more active than female and the center is located at the state capital.

Organic foreign body impaction is commoner in this study. This is because the organic foreign body is very commonly available and used by these children as toys in low-income parents. Common encountered otology foreign body in this study were a cotton bud, seeds, foam, beads, and insects as in other studies ${ }^{[6,18,19]}$. The most common foreign body in this study was cotton bud. This is mostly due to the practice of self ear cleaning and scratching due to itchy ear from allergy oticus or infection as the predisposing factors.

In this study most patients presented with foreign bodies in their right ear followed by left ear while bilateral foreign bodies were found to be the least. Similar predominant right-sided foreign bodies were reported in other studies ${ }^{[8]}$. These findings is supported by the fact that most the studied patients are right- handed. Most of the object were deeply seated in the external auditory canal with few located in middle ear cleft and none in the inner ear. These findings is most likely due to untrained hand intervention.

Asymptomatic patients with otology foreign body impaction are very few in this study. Symptomatic patients usually presented with complaints of foreign body insertion, pain, bleeding as in other studies ${ }^{[2]}$. Most of the pain and bleeding are the consequence of patients, parent and neighborhood attempted removal also reported in other studies ${ }^{[2,20]}$. The object is not removed as a result of this unskilled pre-hospital intervention.

Most of the object are deeply seated in the canal are among referred patients. Referred patients by general practitioners, pediatrician and casualty officer constituted the majority of patients in this study. They mostly referred the impacted foreign bodies after several unsuccessful attempted removal of the object as reported in another study ${ }^{[21]}$.

Recurrence of foreign body impaction is not common in this study. In this study the majority of the patients had a single episode while a minority had recurrent episodes. One of these patients had an allergy as the main reason for frequent self ear scratching.

Duration of presentation from the time of occurrence to when patients presented to specialist depends on the anatomical site, nature of the object, types of symptoms and associated complications. Most of the studied patients presented early as either complicated or severe cases for specialist care. Foreign body in the ear of long standing was covered with earwax.

In this study radiological imaging were requested for a few foreign bodies that was not visualized. The imaging revealed few impacted otology foreign body to be radio-opaque and some to be radiolucent.

Common complications in this study and previous study were bleeding, traumatic perforated tympanic membrane and hearing impairment ${ }^{[22]}$. This occurred from the foreign body or attempted efforts to remove it. 
During the presentation in ear, nose, and throat department patients with living organisms were killed with sterile water, lidocaine solution/spray or oil such as liquid paraffin and olive oil. Techniques of otology foreign body removal depend on the patients and implicated foreign body.

In this study, adopted methods of foreign bodies removal depend on objects nature, size and shape also the anatomical site and extents of the object in the ear other includes patients age and clinical state. The methods used include syringing, suctioning, forceps removal, hooks and probes ${ }^{[23]}$. Important instruments used for otology foreign body removal in this study were a good light source, functioning suction machine, otoscope, different type, and size forceps and suction tips. Appropriate instruments and method in our study reduce further trauma, complications, morbidity, and mortality in our practice. In this study, no anesthesia was required in cooperative patients with visualized otology foreign body. Anesthesia was only given in anxious, unstable with an unvisualized object. The obscure object may be due to bleeding, secretion, tissue penetration and deeper into middle ear cleft.

Though very few patients had recurrent cases in this study. Predisposing factors to foreign body impaction in this study were conservatively and medically treated ${ }^{[8]}$. The intervention includes treatment of earwax impaction, otitis externa, allergy and environmental sanitation against insects and other organisms. This is to prevent avoidable recurrence and complications.

Majority of the complications were secondary to unskilled prehospital interventions. The complications were managed by medical and surgical treatment. Patients, parents, guardian, and caregivers were also educated on predisposing factors and effect of keeping potential foreign body out of reach of children ${ }^{[24]}$. Further on the danger of unskilled pre-hospital intervention on both unsighted or sighted foreign body impaction must be avoided to prevent avoidable complications.

\section{Conclusion}

There are the different type of otology foreign body impaction in all age group and associated predisposing factors. Pre-hospital attempt removal by unskilled sympathizers and untrained health workers leads to avoidable complications. Safe management requires skilled hand, appropriate instruments, with or without anesthesia and treatment of predisposing factors prevent recurrence.

\section{Summary}

- Organic foreign body impaction is commoner in this study. This is because organic foreign body is very commonly available and used by these children as toys in low-income parents.

- Common encountered otology foreign body in this study were a cotton bud, seeds, foam, beads, and insects as in other studies.

- The most common foreign body in this study was cotton bud.

- This is mostly due to the practice of self ear cleaning and scratching due to itchy ear from allergy oticus or infection as the predisposing factors.
- Most patients presented with foreign bodies in their right ear followed by left ear while bilateral foreign bodies were found to be the least.

\section{Funding}

There was no financial support. It is a self-sponsored research study.

\section{Competing interests}

All the authors declare that there were no competing interests..

\section{Acknowledgments}

The authors are most grateful to Ekiti state university teaching hospital and all the patients who participated in this study.

\section{Reference}

[1] Roland NJ, McRae RDR, McCombe AW. Key topics in otolaryngology and head and neck surgery (3rd ed.), BIOS Scientific Publishers, Oxford (2005), p. 104

[2] Ngo A, Ng KC, Sim TP. Otorhinolaryngeal foreign bodies in children presenting to the emergency department. Singapore Med J. 2005;46(4):172-8.

[3] Backlinb SA. Positive pressure technique for nasal foreign body removal in children. Ann Emerg Med, 1995;25(4):554-555.

[4] Afolabi OA, Salaudeen AG, Alabi BS, Lasisi AO. Correlation of aural foreign bodies with handedness: an observational study in a Nigerian tertiary hospital, J. Clin. Med. Res. 2010;2(5):79-82.

[5] Engelsma RJ, Lee WC. Impacted aural foreign body requiring endaural incision and widening for removal, Int. J. Pediatr. Otorhinolaryngol. 1998;44(2):169-171.

[6] Ologe FE, Dunmade AD, Afolabi OA. Aural foreign body in children. Indian J Pediatr 2007;74(8):755-758.

[7] Okafor BC. Trauma to ear including foreign bodies. Nigerian Medical Journal. 1983;13:81-86.

[8] Ijaduola GTA, Okeowo PA. Foreign body in the ear and its importance; the Nigerian experience. J Trop Pediatr. 1986;32:4-6.

[9] Ladapo AA. Danger of foreign bodies in the ear. Niger Med J. 1979;9:120-122.

[10] Takoudes TG, Selesnick SH, Lam SM. Transtympanic penetrating injury to the internal auditory canal. Ann Otol Rhinol Laryngol. 2001;110:696-699.

[11] Skinner DW, Chui P. The hazard of button-sized batteries as foreign bodies in the nose and ear. J Laryngol Otol. 1986;100:1315-1319.

[12] Ezechukwu CC, Nwawolo CC. Removal of ear and nasal foreign bodies where there is no otorhinolaryngologist. Trop Doct. 2005;35:12-13.

[13] Adegbiji WA, Aremu SK, Lasisi AO. Patients Barrier to Ear, Nose and Throat Surgical Care in Nigeria. American Scientific Research Journal for Engineering, Technology, and Sciences (ASRJETS). 2017;32(1):96-104.

[14] Adegbiji WA, Olajide GT, Aremu SK, Alabi SB. Barriers to Adenoid and Tonsil Surgeries in Ekiti, Nigeria. American Journal of Medicine and Medical Sciences. 2017;7(12):385-392. 
[15] Shrestha I, Shrestha BL, Amatya RCM. Analysis of Ear, Nose and Throat Foreign Bodies in Dhulikhel Hospital. Kathmandu Univ Med J 2012;38(2):4-8.

[16] Wada I, Kase Y, Iinuma T. Statistical study on the case of aural foreign bodies. Journal of Otolaryngology of Japan. 2003;106(6):678-684.

[17] Chai CK, Tang IP, Tan TY, Jong DEYH. A review of ear, nose and throat foreign bodies in Sarawak General Hospital. A five-year experience. Medical Journal of Malaysia. 2012;67(1):17-20.

[18] Hon SK, Izam TM, Koay CB, Razi A. A prospective evaluation of foreign bodies presenting to the Ear, Nose and Throat Clinic, Hospital Kuala Lumpur. Medical Journal of Malaysia. 2001;56(4):463-470.

[19] Ryan C, Ghosh A, Wilson-Boyd B, Smit D, O'Leary S. Presentation and management of aural foreign bodies in two Australian emergency departments. Emergency Medicine Australasia. 2006;18(4):372-378.
[20] Zamzil Amin A, Baharudin A, Shahid H. et al. Isolated facial palsy due to intra-aural tick (ixodoidea) infestation. Arch Orofac Sci. 2007;2:51-3.

[21] AA Yaroko and M Irfan. An annual audit of the ear foreign bodies in Hospital universiti Sains Malaysia. Malays Fam Physician. 2012; 7(1): 2-5.

[22] Adegbiji WA, Olajide GT, Olajuyin OA, Olatoke F, Alabi SA, Nwawolo CC. (2018). Traumatic Tympanic Membrane Perforation in Tertiary Health Institution. The Journal of Middle East and North Africa Sciences, 4(01), 8-14.

[23] Ryan C, Ghosh A, Smit D, Boyd WB, O'Leary S. Adult Aural Foreign Bodies. The Inter-net Journal of Otorhinolaryngology 2006;4(2).

[24] Despres N, Lapointe A, Quintal MC, Arcand P, Giguere C, Abela A. 3-Year impact of a provincial choking prevention program. J Otolaryngol. 2006;35(4):216-1. 